\title{
Modelling the factors that influence the acceptance of digital technologies in e- government services in the UAE: A PLS-SEM Approach
}

\author{
Jasimuddin, Sajjad; Kedge Business School, Strategy and Environment \\ Mishra, Nishikant; University of Hull, University of Hull Business School \\ Almuraqab, Nasser; University of Dubai
}

\begin{abstract}
The digital technologies such as internet play a crucial role in the management of operations of organizations in both public and private sectors. Such technologies support the implementation of effective digital business strategies. By reviewing the extant literature, this paper aims to identify factors that influence the intention to use digital technologies in order to develop a theoretical model which is then tested empirically using the PLS-SEM approach. While many studies have focused solely on the importance of social influence, perceived usefulness, perceived ease of use, awareness, perceived trust in technology, perceived trust in government, perceived cost, and perceived risk, this article brings them together to explain their linkage, and quantifies the relationship. This study is the first empirical attempt to explore the factors influence e-government services adoption in the UAE. Most specifically, this article emphasizes the role of social influence, perceived ease to use, and perceived trust in technology as the important determinants of the intention to digital technology adoption. The paper expands the traditional discussion by incorporating six variables, in addition to Davis’s (1989) the perceived ease to digital technologies use and perceived usefulness, in a model that acts as facilitator or barrier in the intention to use digital technologies. This article helps practitioners to understand of which factors should be given emphasis in enhancing the intention to use digital technologies. The model developed in this paper is not only a response to the need to understand what causes the variation in the intention to use digital technologies from the operation management perspective, it is also a response to practitioner needs to use an appropriate construct to ensure the effective operation and use of the digital technologies in e-government services. The paper will help to identify the key
\end{abstract}


issues surrounding the digital technologies adoption that may lead the successful operations of egovernment.

Keywords. Digital technology, ICT, E-government services, technology adoption, UAE

\section{Introduction}

The emerging technological trends are redefining our knowledge about the operations of digital technologies (Schiavone and Sprenger, 2016). The literature has acknowledged the crucial role of digital technology in the management of operations (Tapscott, 1996). The fact that in recent years, the digital technologies such as internet play a significant role in the management of operations of organizations in both public and private sectors. Such technologies support the implementation of effective digital business strategies. the advancement of information and communication technologies (ICT) and particularly the rapid changes in digital technologies have led to the development of new applications and services. The impact of such technologies is so wide that the successful organizations, be it private or public, have undergone a "digital business transformation” in recent years (Bowersox, Closs and Cooper, 2002). Digital technologies improve the operational agility of firms (Sambamurthy, Bharadwaj and Grover, 2003) and support the implementation of effective digital business strategies in particular (Bharadwaj et al., 2013). Electronic-organisations are expected to be one of the promising organisational forms in this Internet cultural era (Azumah et al., 2005). Internet is a critical driver of efficient performance of an organization (Lancioni, Smith and Schau, 2003), and has revolutionised the approach to operations management in industries (Iansiti and Lakhani, 2014; Schiavone and Ferretti, 2016). The adoption of Internet technology can provide manufacturing companies with unprecedented commercial opportunities (Beach, 2004).

Digital technologies have huge potential to be one of the governments' most effective and efficient tools to offer their services to public. Governments around the globe have been providing services to their citizens by means of the internet with different level of success (Al-Khamayseh et al., 2007). Despite the large number of electronic government (e-government) initiatives launched in many parts of the world including UAE, most of these initiatives were met with low rates of acceptance by citizens especially in developing countries (Al-Thunibat et al., 2011a). The 
high reception of mobile devices with over two billion users worldwide has exceeded the usage of personal computer in many countries (Ekong and Ekong, 2010). Such digital technologies have allowed frequent interaction between governments and citizens (Al-Thunibat et al., 2011c). Governments are moving towards digital technologies to improve the level of connection with citizens and improve the nature of service arrangement (Abdelghaffar and Magdy, 2012). Digital technologies are utilized in different fields, for instance, education, healthcare, tourism, transport, and logistics (Ishmatova and Fedotov, 2010).

There are a huge investment made to support the implementation of effective digital business strategies. Policy-makers, practitioners and scholars face the questions relating to the new roles, opportunities and limits of digital technologies within the field of operations management (Schiavone and Sprenger, 2016). The success of the e-government services requires critical engagement between the government and its citizens (Al-Thunibat et al., 2011b). Achieving acceptance of digital technologies in e-government services by citizens is a challenge (Susanto and Goodwin, 2011). Against this backdrop, exploring and understanding the variables that influence the adoption of digital technologies in e-government services is an important research direction (Wu et al., 2009).

Although there is opportunities of digital technologies that are widely discussed in the relevant literature, there is limited research on the perception of the end-users on the intention to use the digital technologies. The understanding of technology acceptance is vital because technology is of little value, unless it is accepted and used (Oye, Iahad and Ab-Rahim 2012). Technology acceptance is about how people adopt digital technology for use. Digital technology acceptance is treated as a function of user involvement in technology adoption.

There has been limited research on factors that influence the end-users' adoption of egovernment services from Western countries perspectives. The lack of knowledge about the endusers' viewpoint may limit the operations of digital technologies. The paper intends to fill this gap by exploring the factors that limit the operations of digital technologies. Giving the rising interest in digital technologies in e-government services in the UAE, this lack of research on the end-users acceptance of digital technologies seems to be a significant gap in our knowledge. Hence, this article will address the issues such as limits of the operations of digital technologies from the endusers' perspective, which is a major concern of the policy-makers, practitioners and scholars. We 
believe this is the first study to examine the influence of key determinants of the end-users' acceptance of digital technologies in the UAE.

The end-users' acceptance of digital technologies is crucial for the effective operation of e-government services. The goal of the paper is to identify the factors that affect the successful adoption of e-government services and develops a conceptual framework relating to the implementation of digital technologies in the UAE. The insights of Davis (1989) inspired the theoretical foundation of this study. The paper will help to understand the key issues surrounding the digital technologies adoption that may lead the successful operations of e-government. The remainder of this paper is organized as follows. First, the various factors that influence the intention to use digital technologies are identified, their relationships are discussed, research hypotheses are developed, and the conceptual framework is presented. The research methodology is then discussed, and the results of the statistical analysis are reported. Following a discussion of the results, the implications and limitations of our work, and directions for future research are outlined.

\section{Literature review and Hypotheses}

It is important to investigate the factors that influence the intention to use digital technologies in e-government (smart government) services among the UAE. The insights of Davis's (1989) the technology acceptance model (TAM) inspired the theoretical foundation of this research. By reviewing the extant literature, this paper identifies several factors that influence the intention to use digital technologies in order to develop a theoretical model which is then tested empirically. Figure 1 depicts the conceptual model that guides the execution of the study, offering an empirical test for eight hypotheses, which are formulated in the following paragraphs.

\section{The intention to use digital technologies in e-government services}

Technology Acceptance Model (TAM) is the most popular theory that explains the technology acceptance factors. Over the last two decades, there has been a wide empirical support in favor of TAM (Dahi and Ezziane, 2015) as of August 2016, Google scholar listed over 30,000 citations of the paper that introduce TAM (Davis, 1989). The present study has used TAM of Davis (1989) so 
as to understand the intention to use digital technologies in e-government services in the context of the UAE. Several scholars (e.g., Abu-Shanab, 2015; Yong Liu et al., 2014; Akhter et al., 2012; Abdelghaffar and Magdy, 2012; Althunibat et al., 2011; Nfuka \& Rusu, 2011; Hussein et al., 2011; Rehman et al., 2012)) have investigated the factors influencing the intention to use the mgovernment services. Mahmud et al., 2015; Abu-Shanab, 2015; Yong Liu et a., 2014; Akhter et al., 2012; Abdelghaffar and Magdy, 2012;Althunibat et al., 2011; Nfuka and Rusu, 2011; Hussein et al., 2011; Rehman et al., 2012).

Abu-Shanab (2015) proposes five factors (i.e., social influence, perceived usefulness, perceived ease of use, perceived compatibility, and perceived responsiveness) are significant in the end-users' intention to use digital technologies. Yong et al. (2014) identify seven factors (i.e., perceived ease of use, perceived usefulness, social influence, image, integrity benevolence, and trust in government) that significantly influence the intention of rural inhabitants to adopt digital technologies in China. Similarly, Abdelghaffar and Magdy (2012) reveal that perceived usefulness, compatibility, awareness, social influence and face-to-face interactions are significant contributors to the prediction of the intention to use e-government in Egypt. Another study by Althunibat et al. (2011) show that nine factors, such as social influence, services quality, perceived usefulness, perceived risk, cost of service, perceived compatibility, trust in government, trust in technology and services quality, are significant towards behavior intention to use the e-government services.

Fig. 1 A conceptual model of the intention to use digital technologies in e-government services 


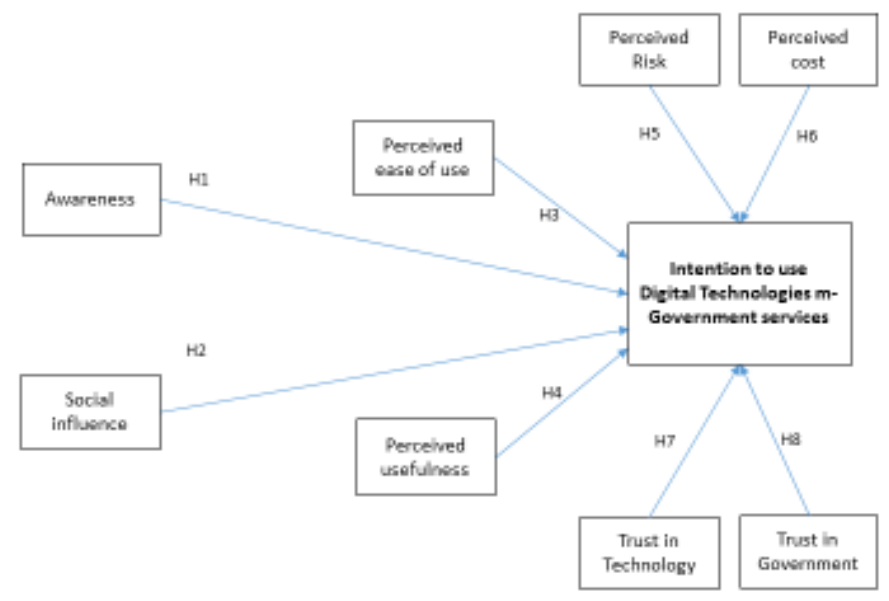

Table -1 Critical Success Factors for Technology Adoption in E-Government Services

\begin{tabular}{|c|c|}
\hline Sources & \begin{tabular}{|c|} 
Critical Success Factors \\
\end{tabular} \\
\hline Abu-Shanab (2015) & $\begin{array}{l}\text { Social influence, perceived usefulness, perceived ease of use, perceived } \\
\text { compatibility, and perceived responsiveness }\end{array}$ \\
\hline $\begin{array}{l}\text { Abdelghaffar and Magdy } \\
\text { (2012) }\end{array}$ & $\begin{array}{l}\text { Perceived usefulness, compatibility, awareness, social influence and face-to-face } \\
\text { interactions }\end{array}$ \\
\hline AlAwadhi \&, Morris (2008) & $\begin{array}{l}\text { Performance expectancy, effort expectancy and peer influence, and facilitating } \\
\text { condition. }\end{array}$ \\
\hline Althunibat et al. (2011) & $\begin{array}{l}\text { Social influence, services quality, perceived usefulness, perceived risk, cost of } \\
\text { service, perceived compatibility, trust in government, trust in technology and } \\
\text { services quality. }\end{array}$ \\
\hline $\begin{array}{l}\text { Choudrie, Weerakkody, \& } \\
\text { Jones (2005) }\end{array}$ & $\begin{array}{l}\text { Lack of internet access, Disparities in computer knowledge, Generation gap, Lack } \\
\text { of awareness, Language barrier, Security fears, Lack of trust, Un-user-friendly web } \\
\text { sites. Lack of finances, Lack of skills and technology, Political pressures, Data } \\
\text { protection and security laws, Staff resistance to change. }\end{array}$ \\
\hline Dahi M. , Ezziane Z. (2015) & Perceived usefulness, perceived ease of use, subjective norms, and trust. \\
\hline Ebrahim and Irani (2005) & ICT infrastructure, Organizational and operational cost. \\
\hline Hussein et al. (2011) & $\begin{array}{l}\text { Perceived ease of use and perceived usefulness, trust of the government, image, } \\
\text { compatibility and service quality. }\end{array}$ \\
\hline Ifinedo \& Singh (2011) & $\begin{array}{l}\text { Higher levels of human capital resources, Rule of law, The availability of ICT } \\
\text { infrastructure, Transparency levels, National wealth and government efficiency }\end{array}$ \\
\hline
\end{tabular}




\begin{tabular}{|l|l|}
\hline Mahmud et al. (2012) & $\begin{array}{l}\text { Perceived ease of use, Perceived security, perceived reliability, and Relative } \\
\text { Advantage }\end{array}$ \\
\hline Nfuka \& Rusu (2011) & $\begin{array}{l}\text { Strategic alignment, Value delivery, risk management, Resource management, } \\
\text { Performance measurement }\end{array}$ \\
\hline Rehman et al. (2012) & $\begin{array}{l}\text { Information quality, awareness, perceived ease of use, service quality and transaction } \\
\text { security. }\end{array}$ \\
\hline Yong et al. (2014) & Perceived ease of use, perceived usefulness, social influence, image, integrity \\
& benevolence, and trust in government. \\
\hline
\end{tabular}

\section{Awareness}

Awareness of the end-users is the people's knowledge about digital technologies (Venkatesh et al., 2003; Al-adawi et al., 2005; Mofleh and Wanous, 2008). Awareness is the first step for users to know the availability of electronic devices in e-government services (Abdelgaffar and Magdy, 2012). Indeed, people's awareness of e-government services and the availability of electronic resources is a major concern. The lack of awareness is found to have a negative impact on citizens' intention to adopt the technologies in e-government services (Rehman et al., 2012; Anas et al., 2014; Alateyah et al. 2014), and therefore, leads to declining the interest of e-government services. Several authors (e.g. Dahi and Ezziane, 2015; Khalil and Al-Nasrallah, 2014) agree that the lack of awareness is one of the main obstacle towards successful adoption of digital technologies.

Scholars (e.g. Anas et al., 2014) argue that without citizens’ awareness, acceptability and usage of the e-government services, the government cannot achieve its objectives of providing such services. Napitupulu and Sensuse (2014) contend that awareness is one of the critical success factors in e-government services implementation. Interestingly, Dahi and Ezziane (2015) maintain that in the UAE, many end-users are not aware of the digital technologies available to use in the e-government services. But there is a relationship between awareness and intention to adopt technologies in e-government services by citizens (Rehman et al., 2012). Therefore, we have formulated the following hypothesis:

Hypothesis 1: Awareness will have a positive impact on user's intention to digital technologies use in the e-government services.

\section{Social influence}

Social influence has a significant influence to the end-user's intention to use digital technologies in e-government services. Social influence is the degree to which an individual perceives 
importance of system through that the influence of others (e.g., family and friends) (Venkatesh et al., 2003). Social influence is one of the major factors of the intention to technology use in egovernment services (Althunibat et. al, 2011). This variable integrates the social influence and subjective norm as well (Abu-Shanab, 2015). It is vital to realize the importance of friends and family in the decision of adopting a technology. Dahi and Ezziane (2015) state that the end-users would like to use government services portal in future, if their friends and colleagues use them. Social influence is critical to realize the importance of friends, family, and important stakeholders in the decision of utilizing a technology. Al-Thunibat et al. (2011) also argue that social influence is one of the major predictors of the intention to use digital technologies in the m-government service. Based on these arguments, the following hypothesis can be proposed:

Hypothesis 2: Social influence will have a positive impact on user's intention to digital technologies use in the e-government services.

\section{Perceived ease of use}

Perceived ease to use is the extent to which an end-user believes that a particular system would be used without much hassle and effort (Davis, 1989). The digital technologies will get more acceptance if it is easy to use (Dahi and Ezziane, 2015). Several scholars (e.g. Yong et al., 2014; Al-Thunibat, 2011; Abu-Shanab (2015) argue that the end-users would like to use the digital technologies in m-government services because it is practical, simple, easy to access, less hassle, easy to use. Other authors (i.e., Dahi and Ezziane, 2015; Alomari et al., 2012; Mahmud et al., 2012) have reported that the perceived ease to use has a significant impact on the adoption of digital technology in e-government services. Althunibat et al. (2015) state that the greater perceived ease of use technology in e-government services the more the people will intend to use technology. Hence, the perceived ease to technology use may have influence on an end-user's intension of its usefulness. Based on these arguments, we make the following hypothesis:

Hypothesis 3: Perceived ease to use digital technology will have a positive impact on enduser's intention to technology use in the e-government services.

\section{Perceived usefulness}


Perceived usefulness is the extent to which an end-user believes that using a particular system would enhance his job performance (Davis, 1989). Perceived usefulness is a strong determinant in technology adoption (Althunibat et. al, 2011). It is argued that people has high intention to use digital technology if they perceive its usefulness. The more the technology in e-government services are perceived useful, the more the intention to adopt technology. In this regard, Alomari et al. (2012) state that the higher level of perceived usefulness is positively linked with the increased intention to use e-government portals. In view of these arguments, we make the following hypothesis:

Hypothesis 4: Perceived usefulness of digital technology will have a positive impact on end-user's intention to technology use in the e-government services.

\section{Perceived risk.}

Perceived risk is another important variable that affects an end-user's intention to use digital technologies. According to Carter and Be'langer (2005), perceived risk is the citizen's subjective expectation of suffering a loss in pursuit of a favorite outcome. It is no doubt that citizens' behavior is intensely affected by perception of risk. Bauer (1976) agrues that the end-users are frequently uncertain about the consequences of a decision or an action. The growing worries such as identity theft and hacking are obvious which make end-users to think twice before adopting digital technologies. Chen (2008) highlights security as a big issue, and such matter needs to be addressed. Hence, an end-user's subjective risk perception can strongly explain her/his behavior (Mitchell 1999). Based on the analysis above, the following hypothesis is presented:

Hypothesis 5: Perceived risk will have a negative impact on user's intention to use technology in e-government services.

\section{Perceived cost}

Digital technologies are relatively costly which has an influence to the end-users' intention to use such technologies. Perceived cost is found to negatively affect the user's intention to adopt technology. The fact is that the cost of accessing wireless service (e.g. subscription, service charge, and communication fees) is higher than that of accessing wired internet services e.g. personal computer (Bong-Keun and Tom, 2013). Hence, several scholars ((Kuo and Yen, 2009; Luarn and Lin, 2005; Wu and Wang, 2005; El Kiki \& Lawrence, 2007) argue that financial considerations 
may influence consumers' behavioral intentions to use the digital technologies in e-government services. It has a negative effect on behavioral intention to use technology. The above discussion leads to the following hypothesis:

Hypothesis 6: Perceived cost will have a negative impact on user's intention to use technology in the e-government services.

\section{Perceived Trust in government}

Trust in government is another important factor that influences an end-user's intention to technology use. Many people believe that the government treats itself as as big brother, arguing that government is surrounding citizens all the time, and breach upon their personal lives (Althunibat et al., 2011). Several authors (e.g., Rehman et al., 2012; Carter \& Bélanger, 2005) argue that the end-users must have confidence in the government. The lack of trust in government in relation to technologies may discourage their intension to use digital technologies. The fact that the higher level of trust in government the more of users' adoption of e-government website portal and its services in Jordan (Alomari et al., 2012). Dahi and Ezziane (2015) argue that the intention of users is largely explained by trust on government services in UAE. Therefore, in our model, this construct is proposed to have a relationship to the user's intention to use digital technologies in egovernment services. Based on these arguments, we have formulated the following hypothesis:

Hypothesis 7: Perceived Trust in government will have a positive impact on user's intention to use technology in the smart-government services.

\section{Perceived Trust in Technology}

Trust in technology is also recognized as a key factor of the intention to use digital technologies. Several authors (e.g., McKnight, 2002; Pavlou, 2003; Warkentin et al., 2002; Welch et al., 2005) label such kind of trust as institution-based trust. The end-users must have confidence in the enabling technologies (Carter \& Be'langer, 2005). Based on the analysis above, the following hypothesis is presented:

Hypothesis 8: Trust in Technology will have a positive impact on user's intention to digital technologies use in et-government services.

\section{Research Method}


Partial Least Square Structural equation modeling (PLS-SEM) is a promising methodology of statistical data analysis that exists at the interaction of regression models and structural equation modeling (Becker et al., 2013; Jasimuddin et al., 2015a). The PLS-SEM is widely used in information systems, strategic management, marketing research and beyond (Hair et al., 2012; Henseler et al., 2016). Valle and Assaker (2015) argue that the number of empirical applications of PLS-SEM in management studies including tourism has increased, which is capable of handling simultaneity. PLS-SEM is applied to test the research hypotheses. The PLS-SEM approach will allow us to perform path-analytic modeling with latent variables. The fact that the structural model assessment offer to test the path coefficients, i.e., direct and indirect effects between latent variables (Tubadji and Nijkamp, 2015). This study employs PLS-SEM approach to examine the complex research model and hypotheses collectively. Most specifically, this approach is used in this study to offer an analysis of the relationships between the constructs (e.g., social influence, perceived usefulness, perceived ease of use, awareness, perceived trust in technology, perceived trust in government, perceived cost, and perceived risk, and intention to use digital technologies) and determine the predictive power of the model. The units of analysis in this study were the endusers of digital technologies in e-government services.

\section{Research setting}

UAE government intends to provide its citizens (end-users) with more accessible, accurate, realtime and high quality services and information with the use of smart devices (digital technologies) which includes high-speed wireless internet connections. With the introduction of Smart Government initiative, citizens will be able to access e-government services using mobile technologies such as mobile phones. The fact that Wi-Fi enabled devices and wireless networks expedites the efficient operation and delivery of public services (Ghyasi and Kushchu, 2004).

A multi-industry sampling design was used to broaden the generalizability of the findings (Katsikea et al. 2011; Islam el al., 2015) and included education, manufacturing and service sectors. The data collection process resulted in 83 useable questionnaires, with a response rate of $66.4 \%$. The respondents were the UAE citizens and residence. The questionnaire used in this research was developed on the basis of the literature review. 
Initially, the questionnaire was piloted using 35 respondents to increase the clarity of the questions and to avoid interpretation errors. Moreover, it was translated and back-translated to ensure that the Arabic translation accurately reflected the meaning of the English version and to reduce comprehension problems (Sperber et al. 1994). The questionnaire consisted of 45 questions, most of which used a five-point Likert-type scale to measure responses. All respondents had similar backgrounds and were likely to aware and use digital technologies in e-government services. Most respondents were university educated (85.5\%), male (59\%) and in the 30+ age group (79.2\%). Table 2 shows the demographic information.

Table 2 Demographic of the sample used

\begin{tabular}{|l|l|l|}
\hline Gender & Frequency & Percentage \\
\hline Female & 34 & $41 \%$ \\
\hline Male & 49 & $59 \%$ \\
\hline Education level & & \\
\hline High school or less & 3 & $3.6 \%$ \\
\hline Diploma & 9 & $10.8 \%$ \\
\hline Bachelor & 31 & $37.3 \%$ \\
\hline Master or PhD & 40 & $48.1 \%$ \\
\hline Age & & \\
\hline $17-30$ & 22 & $26.5 \%$ \\
\hline $31-45$ & 53 & $63.8 \%$ \\
\hline $46-60$ & 7 & $8.4 \%$ \\
\hline More than 60 & 1 & $1.2 \%$ \\
\hline & & \\
\hline
\end{tabular}

\section{Measurement}

Measurement of the constructs involved the use of multi-item reflective scales, which enhances confidence so that the measurement of the construct is consistent (Churchill, 1979). A review of 
the relevant literature was undertaken to develop multiple items of all constructs of interest. There are certain scales which are repeatedly used in most empirical investigations. All measures were assessed via a five-point interval scale ranging from ' 1 = strongly disagree’ to ‘ 5 = strongly agree.' This format was used for all the scales described below. The questionnaire contained 49 items measuring nine constructs (including the intention to use digital technologies), plus seven items at the beginning of the questionnaire to gather background information.

The key factors relating to intention to use digital technologies were captured by social influence, perceived usefulness, perceived ease of use, awareness, perceived trust in technology, perceived trust in government, perceived cost, and perceived risk dimensions. Each dimension was made up of several items in order to measure a scale.

Awareness was measured on a scale that was developed using the related literature (e.g., Abdelgaffar and Magdy, 2012 Rehman et al., 2012; Anas et al., 2014; Alateyah et al. 2014; Dahi and Ezziane, 2015; Khalil and Al-Nasrallah, 2014). The scale (composite reliability $=0.915$ ) consisted of three items. Social influence was assessed using a three-item scale, drawn from the relevant literature (e.g., Venkatesh et al., 2003; Althunibat et al., 2011; Abu-Shanab, 2015 ; Dahi and Ezziane, 2015). The composite reliability is 0.959 .

There are different instruments to measure perceived ease of digital technologies use. We used a four-item scale to measure perceived ease of digital technologies use, which was adapted from others' work (e.g., Davis, 1989; Althunibat et. al, 2011; Alomari et al., 2012). The composite reliability is 0.96. Perceived usefulness of digital technologies was assessed using a five-item scale, drawn from the relevant literature (e.g., Davis, 1989; Dahi and Ezziane, 2015; Alomari et al., 2012; Mahmud et al., 2012 ; Abu-Shanab, (2015). The composite reliability is 0.968.

Perceived risk of using digital technologies was measured on a scale that was developed using the related literature (e.g., Carter and Be'langer, 2005; Mitchell 1999; Bauer, 1976; Chen, 2008). The scale (composite reliability $=0.937$ ) consisted of five items. There are different instruments to measure perceived cost of using digital technologies. We used a three-item scale to measure (e.g., Bong-Keun and Tom, 2013; Kuo and Yen, 2009; Luarn and Lin, 2005; Wu and Wang, 2005; El Kiki and Lawrence, 2007). The composite reliability is 0.933.

Perceived trust in technology was assessed using a five-item scale, drawn from the relevant literature (e.g., McKnight, 2002; Pavlou, 2003; Warkentin et al., 2002; Welch et al., 2005; Carter \& Be'langer, 2005). The composite reliability is 0.921 . Perceived trust in government was 
measured on a scale that was developed using the related literature (e.g., (Althunibat et al., 2011 ; Rehman et al., 2012; Carter \& Be'langer, 2005; Alomari et al., 2012). Dahi and Ezziane, 2015). The scale (composite reliability $=0.921$ ) consisted of three items.

Finally, the dependent variable, Intention to use digital technologies, was assessed using a three-item scale, drawn from the relevant literature (e.g., Davis, 1989’ Dahi and Ezziane, 2015. Abu-Shanab, 2015; Yong Liu et a., 2014; Akhter et al., 2012; Abdelghaffar and Magdy, 2012; Althunibat et al., 2011) The composite reliability is 0.959 .

\section{Data Analysis and Results}

Partial Least Square Structural Equation Modelling (PLS- SEM) using SmartPLS 3 application helps to evaluate the reliability and validity of the measurement model (Ringle, Wende, \& Will, 2005). PLS-SEM evaluates the measurement and structural models concurrently, therefore running factor analysis to assess the convergent and discriminant validity, and hypothesis testing at the same time (Gefen, Straub, \& Boudreau, 2000). These will be discussed later.

\section{The Results of the Measurement Model}

To test the measurement model, we assessed both convergent and discriminant validities. Convergent validity was supported after examining Cronbach’s alpha, composite reliabilities, average variance extracted (AVE), and item loadings Table 3 summarizes the variables used in this study and displays the means, standard deviations, and the item loadings. Each of the measurement items should significantly load on its latent construct (Gefen et al., 2000). Our factor loadings ranged from 0.791 to 0.956 , all of which exceed the cutoff value of 0.5 , recommended by Straub (1989).

The internal reliability of the measurement model can be tested using Cronbach's alpha (Fornell \& Larcker, 1981). The Cronbach alpha should be greater than 0.7 to indicate a strong reliability for a questionnaire content (Cuieford, 1965; Nunnally, 1978). In this study, the Cronbach's alpha of each construct was greater than 0.7. The smallest at 0.846 indicates a strong reliability for our questionnaire content.

Convergent validity was assessed by examining the average variance extracted (AVE) and the composite reliability. Composite reliability values should be 0.6 as a cutoff value (Bagozzi and 
Yi, 1988). In our study, all composite reliability values exceeded the recommended threshold value, ranging from 0.907 (trust in government) to 0.968 (perceived usefulness of digital technology), demonstrating composite reliability.

Table 2 Factoring loading, means and standard deviations of all items used

\begin{tabular}{|c|c|c|c|c|c|c|c|c|c|c|c|}
\hline & AW & ITU & PCst & PEOU & PR & PU & SI & TiG & TiT & Mean & SD \\
\hline AW1 & 0.894 & & & & & & & & & 4.072 & 1.057 \\
\hline AW2 & 0.944 & & & & & & & & & 3.880 & 1.130 \\
\hline AW3 & 0.811 & & & & & & & & & 3.241 & 1.164 \\
\hline ITU1 & & 0.91 & & & & & & & & 4.181 & 1.026 \\
\hline ITU2 & & 0.953 & & & & & & & & 4.060 & 1.108 \\
\hline ITU3 & & 0.96 & & & & & & & & 3.771 & 1.130 \\
\hline PCst1 & & & 0.918 & & & & & & & 3.940 & 0.954 \\
\hline PCst2 & & & 0.922 & & & & & & & 4.217 & 0.938 \\
\hline PCst3 & & & 0.879 & & & & & & & 4.253 & 0.935 \\
\hline PEOU1 & & & & 0.917 & & & & & & 4.193 & 0.981 \\
\hline PEOU2 & & & & 0.929 & & & & & & 4.386 & 0.881 \\
\hline PEOU3 & & & & 0.915 & & & & & & 4.434 & 0.872 \\
\hline PEOU4 & & & & 0.942 & & & & & & 3.952 & 1.023 \\
\hline PR1 & & & & & 0.843 & & & & & 3.928 & 0.960 \\
\hline PR2 & & & & & 0.902 & & & & & 4.084 & 0.872 \\
\hline PR3 & & & & & 0.898 & & & & & 4.205 & 0.921 \\
\hline PR4 & & & & & 0.893 & & & & & 4.325 & 0.871 \\
\hline PR5 & & & & & 0.784 & & & & & 4.193 & 0.956 \\
\hline PU1 & & & & & & 0.896 & & & & 3.181 & 1.181 \\
\hline PU2 & & & & & & 0.933 & & & & 3.470 & 1.028 \\
\hline PU3 & & & & & & 0.917 & & & & 3.048 & 1.287 \\
\hline PU4 & & & & & & 0.951 & & & & 3.578 & 1.037 \\
\hline
\end{tabular}




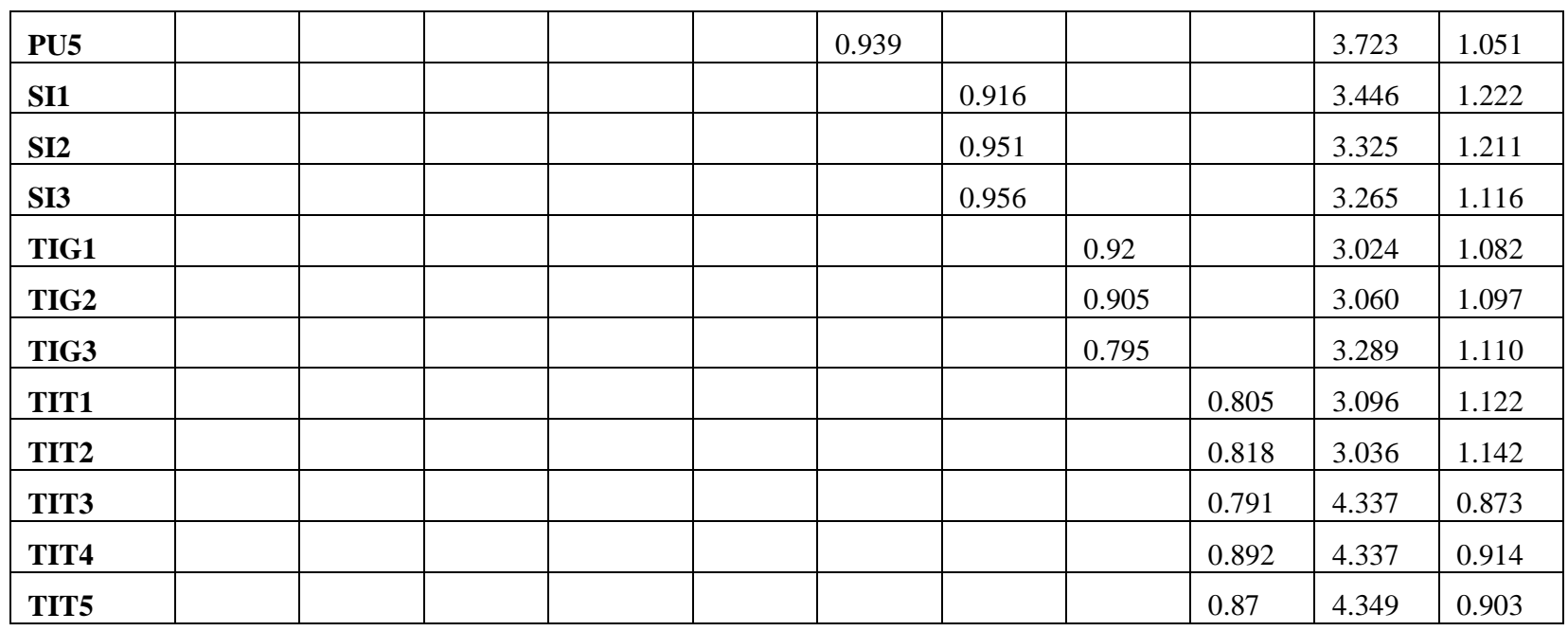

According to several scholars (e.g., Hair, Anderson, Tatham, \& Black, 1998), the AVE values should be greater than 0.5 to validate convergent validity. As shown in Table 4, All AVE exceeded the recommended threshold value of 0.5, ranging from 0.749 (perceived risk) to 0.886 (intension to use digital technology), again demonstrating convergent validity.

Table 4 Cronbach Alpha, Composite reliability and average variance extracted

\begin{tabular}{|l|l|l|l|}
\hline & Cronbach Alpha & Composite Reliability & AVE \\
\hline AW & 0.863 & 0.915 & 0.783 \\
\hline ITU & 0.935 & 0.959 & 0.886 \\
\hline PCst & 0.894 & 0.933 & 0.822 \\
\hline PEOU & 0.944 & 0.96 & 0.857 \\
\hline PR & 0.92 & 0.937 & 0.749 \\
\hline PU & 0.959 & 0.968 & 0.86 \\
\hline SI & 0.935 & 0.959 & 0.885 \\
\hline TiG & 0.846 & 0.907 & 0.766 \\
\hline TiT & 0.896 & 0.921 & 0.699 \\
\hline
\end{tabular}

To establish construct discriminant validity, Fornell \& Larcker (1981) state that the square root of Average Variance Extracted (AVE) needs to be higher for that construct than its correlation with other constructs. Table 5 shows the inter-construct correlation matrix and the square root of Average Variance Extracted (AVE).

Table 5 Correlation matrix

\begin{tabular}{|l|l|l|l|l|l|l|l|l|l|}
\hline & AW & ITU & PCst & PEOU & PR & PU & SI & TiG & TT \\
\hline AW & $\mathbf{0 . 8 8 5}$ & & & & & & & & \\
\hline
\end{tabular}




\begin{tabular}{|l|l|l|l|l|l|l|l|l|l|}
\hline ITU & 0.59 & $\mathbf{0 . 9 4 1}$ & & & & & & & \\
\hline PCst & 0.101 & 0.226 & $\mathbf{0 . 9 0 7}$ & & & & & & \\
\hline PEOU & 0.738 & 0.679 & 0.141 & $\mathbf{0 . 9 2 6}$ & & & & & \\
\hline PR & -0.069 & 0.154 & 0.618 & 0.036 & $\mathbf{0 . 8 6 5}$ & & & & \\
\hline PU & 0.56 & 0.527 & 0.141 & 0.788 & 0.107 & $\mathbf{0 . 9 2 7}$ & & & \\
\hline SI & 0.355 & 0.523 & 0.091 & 0.498 & 0.179 & 0.584 & $\mathbf{0 . 9 4 1}$ & & \\
\hline TiG & 0.471 & 0.538 & 0.166 & 0.627 & 0.135 & 0.584 & 0.634 & $\mathbf{0 . 8 7 5}$ & \\
\hline TiT & 0.541 & 0.545 & 0.158 & 0.533 & -0.125 & 0.341 & 0.328 & 0.52 & $\mathbf{0 . 8 3 6}$ \\
\hline
\end{tabular}

\section{The Results of Hypotheses Testing}

As mentioned earlier, PLS-SEM analysis is used in this paper to test the hypotheses, using statistical software SmartPLS 3 version. Table 6 summarizes the parameter estimates, significance levels, and hypotheses test results. The procedure allows us to investigate the relationship between key factors of that influence the acceptance of digital technologies in e-government services.

Hypothesis 1 predicts that the awareness of the end-users will have a significant impact on the end-users' intention to use digital technologies in e-government services. Interestingly, the result gives contradictory picture. The standardized coefficients of awareness of the end-users and the end-users' intention to use are -0.154 , and the $t$-value is $1.301, p<1.93$, indicating statistical insignificance. Thus, Hypothesis 1 is not supported.

Hypothesis 2 proposes that the social influence on the end-users has a significant relationship with the end-users' intention to use digital technologies. The standardized coefficients of social influence on the end-users and the end-users' intention to use technology are -0.24 , and the $t$-value is 1.831, $p<0.067$, indicating statistical significance. Thus, Hypothesis 2 is fully supported.

Hypothesis 3 suggests that there is a significant positive relationship between perceived ease of digital technologies use and the end-users' intention to use digital technologies. The standardized coefficients of perceived ease of digital technologies use and the end-users' intention to use digital technologies are -0.422 , and the $t$-value is $2.292, p<0.022$, indicating statistical significance. Thus, Hypothesis 3 is fully supported.

Hypothesis 4 predicts that the perceived usefulness has positive influence on the end-users' intention to digital technologies use. That is, there is significant positive relationship between the perceived usefulness and the end-users' intention to use digital technologies. The standardized coefficients of perceived usefulness and the end-users' intention to use digital technologies are 
-0.112 , and the $t$-value is $0.606, p<0.544$, which is not statistically significant. Thus, Hypothesis 4 is not supported.

Hypothesis 5 proposes that there is a negative relationship between perceived risk of using digital technologies and the end-users' intention to digital technologies use. The standardized coefficients of perceived risk and the end-users' intention to use are 0.127 , and the $t$-value is 1.139 , $p<0.255$, indicating statistical insignificance. Thus, Hypothesis 5 is not supported.

Hypothesis 6 predicts that perceived cost of using digital technologies has a significant impact on the end-users' intention to use digital technologies. The standardized coefficients of perceived risk and the end-users' intention to use are 0.036, and the $t$-value is $0.368, p<0.713$, indicating statistical insignificance. Thus, Hypothesis 6 is not supported.

Hypothesis 7 suggests that there is a positive relationship between perceived trust in digital technologies and the end-users' intention to use such technologies. The standardized coefficients of perceived trust and the end-users' intention to use are -0.022 , and the $t$-value is $0.161, p<0.872$ reaching indicating statistically significant.. The results indicate that there is significant relationship between perceived trust and the end-users' intention to use. Thus, Hypothesis 7 is fully supported.

Hypothesis 8 suggests that perceived trust in government and the end-users' intention to use digital technologies. The standardized coefficients of perceived trust in government and the endusers' intention to use are -0.217 , and the $t$-value is $2.259, p<0.024$, , indicating statistical insignificance. The results suggest that there is significant relationship between perceived trust and the end-users' intention to use. Thus, Hypothesis 8 is fully supported.

\section{Table 6 Hypotheses Testing Results}

\begin{tabular}{|c|c|c|c|c|}
\hline Hypothesis & $\begin{array}{l}\text { Path } \\
\text { coefficient }\end{array}$ & T Value & $\begin{array}{l}\mathbf{P} \\
\text { Value }\end{array}$ & $\begin{array}{l}\text { Hypothesis } \\
\text { status }\end{array}$ \\
\hline $\begin{array}{l}\text { H1: Awareness is positively effect on users' } \\
\text { intention to use smart government services. }\end{array}$ & 0.154 & 1.301 & 0.193 & Not supported \\
\hline $\begin{array}{l}\text { H2: Social influence is positively effect on } \\
\text { users' intention to use smart government } \\
\text { services. }\end{array}$ & 0.240 & 1.831 & 0.067 & orted * \\
\hline $\begin{array}{l}\text { H3: Perceived ease of use is positively effect } \\
\text { on users' intention to use smart government } \\
\text { services }\end{array}$ & 0.422 & 2.292 & 0.022 & Supported ${ }^{* *}$ \\
\hline $\begin{array}{l}\text { H4: Perceived usefulness effect positively on } \\
\text { users' intention to use the smart government } \\
\text { services }\end{array}$ & -0.112 & 0.606 & 0.544 & Not supported \\
\hline
\end{tabular}




\begin{tabular}{|c|c|c|c|c|}
\hline $\begin{array}{l}\text { H5: Perceived risk effect negatively on users' } \\
\text { intention to use the smart government services }\end{array}$ & 0.127 & 1.139 & 0.255 & Not supported \\
\hline $\begin{array}{l}\text { H6: Perceived cost effect negatively users' } \\
\text { intention to use the smart government services }\end{array}$ & 0.036 & 0.368 & 0.713 & Not supported \\
\hline $\begin{array}{l}\text { H7: Trust in technology effect positively on } \\
\text { users' intention to use the smart government } \\
\text { services }\end{array}$ & -0.022 & 2.259 & 0.024 & Supported** \\
\hline $\begin{array}{l}\text { H8: Trust in Government effect positively on } \\
\text { users' intention to use the smart government } \\
\text { services }\end{array}$ & 0.217 & 0.161 & 0.872 & Not supported \\
\hline
\end{tabular}

$$
{ }^{*} \mathbf{p}<.1, * * \mathbf{p}<.05, * * * \mathbf{p}<.01
$$

\section{Discussion}

This paper sets out to investigate the impact of the key factors on the intention to use digital technologies in e-government services. The empirical results derived from this study warrant a discussion along several lines. The results of our PLS analysis are shown in Figure 2. The key factors identified are crucial, which can either enhance or hinder the intention to use digital technologies in -government services.

\section{Figure 2 Analytical Results}

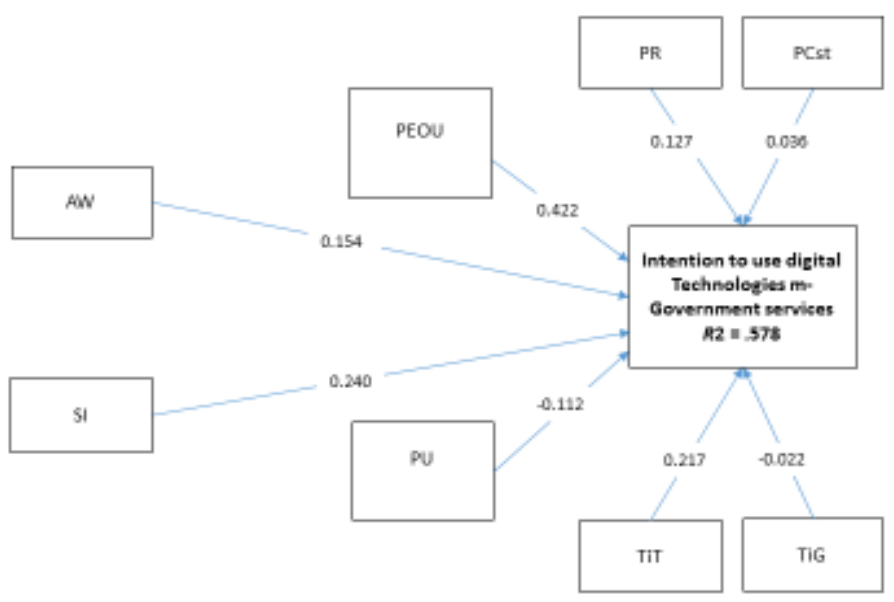


Social influence is the most significant determinant of the intention to use digital technologies in e-government services. Moreover, perceived ease to digital technologies and trust in technology can motivate the end-users to use digital technologies. Similarly, the perceived trust in technology has an important role in the intention to use digital technologies. This article confirms others’ work (Venkatesh et al., 2003; Althunibat et al., 2011; Abu-Shanab, 2015 ; Dahi and Ezziane, 2015; Davis, 1989; Alomari et al., 2012; McKnight, 2002; Pavlou, 2003; Warkentin et al., 2002; Welch et al., 2005; Carter \& Be'langer, 2005) that social influence, perceived ease to digital technologies and trust in technology have strong impact on the intention to use digital technologies. the study provides an interesting finding on awareness of the end-users. Similarly, the result shows that awareness has no impact on intension to use digital technologies. The paper reveals that cost involved in using digital technologies have no implication on the Emiraties' intention to use digital technologies. They are relatively rich and their par capita income is above 50 thousand US dollar. Moreover, perceived risk and perceived trust in government have no impact on the intention to use digital technologies. It is to be noted that the $R^{2}$ indicates the fraction of total variance in the dependent variable accounted for by those independent (Jasimuddin et al., 2005a). Thus, the bigger the $R^{2}$, the more the predictive power of the framework (Weinfurt, 1995; Jasimuddin et al., 2005b). Overall, a substantial amount of variance is explained in the dependent variable, the intention to use digital technologies. Its $R^{2}$ value of 0.578 indicates that a substantial proportion of variance of the intention to use digital technologies was, indeed, predicted by those eight factors.

This article makes several contributions to the literature. This study is the first empirical attempt to explore the factors influence smart e-government services adoption in UAE. We contribute to the conceptualization of the intention to use digital technologies in e-government services. The paper emphasizes the role of social influence, perceived ease to use, and perceived trust in technology as the important determinants of the intention to use digital technologies. The paper expands the traditional discussion by incorporating six variables, in addition to Davis's (1989) the perceived ease to digital technologies use and perceived usefulness, in a model that acts as facilitator or barrier in the intention to use digital technologies. We propose and test an integrated framework in which social influence, perceived ease to use, and perceived trust in technology have direct impact on the intention to use digital technologies. The construct associated 
with awareness has no direct impact on the intention to use digital technologies. While many studies have focused solely on the importance of social influence, perceived usefulness, perceived ease of use, awareness, perceived trust in technology, perceived trust in government, perceived cost, and perceived risk, this article brings them together to explain their linkage, and quantifies the relationship.

This article helps practitioners to understand of which factors should be given emphasis in enhancing the intention to use digital technologies. This study can also be seen to provide managers and practitioners with an understanding that the cost has no impact on the facilitation and inhibition of an end-user's intention to use digital technologies, whil social influence has a great role. Hence, the research findings suggest that key constructs in various forms are issues in causing the variation in the intention to use digital technologies. However, the model developed in this paper is not only a response to the need to understand what causes the variation in the intention to use digital technologies from the operation management perspective, it is also a response to practitioner needs to use an appropriate construct to ensure the effective operation and use of the digital technologies in m-government services.

\section{Limitations and Future Research Directions}

Although this study presents strong evidence regarding the identification of the key factors that influence on the end-user's intension of the digital technologies in m-government services, it should also be assessed in light of its limitations. First, our research did not cover comprehensively all the factors that influence the end-users' intension of using the digital technologies in $\mathrm{m}$ government services. For example, there are important variables such facilitating condition and perceived compatibility are relevant variables. Moreover, age, gender, education and profession can be controlled for. Hence, these variables are being taken into account in future work. Secondly, the research model and hypotheses were tested, using data drawn only from in a single country (i.e., UAE), and the results are therefore limited to this country. In order to generalize the results, the study may be expanded to other Middle Eastern and developing countries settings. Thirdly, the cross-sectional nature of this research may inhibit the testing of causality between the constructs included in the research model. Thus, longitudinal studies using causal research designs would be useful. Fourthly, only the views of digital technology users based in the UAE were considered in 
the subjective instruments used to discuss the factors that influence the adoption of digital technology. This may lead to biased results since the views of e-government service providers may be different. To ensure robust results, these views should be considered in a future study.

\section{Conclusions}

The adoption of digital technologies is crucial in the management of operations of organizations in e-government services. Such technologies support the implementation of effective digital business strategies. By using the PLS-SEM approach, this paper identifies several factors that influence the intention to use digital technologies and develops a theoretical model which is then tested empirically. This study is the first empirical attempt to explore the factors influence egovernment services adoption in the UAE. Most specifically, this article emphasizes the role of social influence, perceived ease to use, and perceived trust in technology as the important determinants of the intention to use digital technologies. The paper expands the traditional discussion by incorporating six variables, in addition to Davis's (1989) the perceived ease to digital technologies use and perceived usefulness, in a model that acts as facilitator in the intention to use digital technologies. This paper reveals which factors have statistically significant effect on the intension to use of the digital technologies in e-government services by testing eight hypotheses. This article brings the eight constructs together to explain their linkage and quantified the relationship.

The model developed in this paper is not only a response to the need to understand what causes the variation in the intention to use digital technologies from the operation management perspective, it is also a response to practitioner needs to use an appropriate construct to ensure the effective operation and use of the digital technologies in e-government services. This article helps practitioners to understand of which factors should be given emphasis in enhancing the intention to use digital technologies. The paper will help to identify the key issues surrounding the digital technologies adoption that may lead the successful operations of e-government.

\section{References}


1. Abu-Shanab, E. 2015. “Major factors influencing the adoption of m-government in Jordan”. Electronic Government An International Journal 11(4): 223-240.

2. Althunibat, A., M. Azan, and N. Sahari. 2011. "Modelling the factors that influence mobile government services acceptance”. African Journal of Business Management 5(34): 13030-13043.

3. AlAwadhi S. and A, Morris. 2008. "The Use of the UTAUT Model in the Adoption of E-government Services in Kuwait”. Proceedings of the 41st Hawaii International Conference on System Sciences.

4. Azumah G. S. C. L. Koh, and S. Maguire. 2005. “E-organisation and its future implication for SMEs”. Production Planning \& Control 16(6): 555-562.

5. Abu-Shanab, E. 2015. "Major factors influencing the adoption of m-government in Jordan”. Electronic Government An International Journal, 11(11): 223-240.

6. Abdelghaffar, H. and Y. Magdy. 2012. 'The adoption of mobile government services in developing countries: the case of Egypt”. International Journal of Information and Communication Technology Research, 2(1): 333-341.

7. Al-Hujran, O. 2012. 'Towards the utilization of m-government service in developing countries: a qualitative e-investigation”. International Journal of Business and Social Science, 3(5): 155-160.

8. Al-khamayseh, S., E. Lawrence. and A, Zmijewska. 2007. “Towards understanding success factors in interactive mobile government”. Proceedings of the Second European Conference on Mobile Government (Euro mGov) - Opportunities for eGovernment: Adapting to Mobile and Ubiquitous Business 3-5.

9. Alomari M., P. Woods. K. Sandhu. 2012. “Predictors for e-government adoption in Jordan”. Information Technology \& People 25(2): 207 - 234.

10. Al-Thunibat, A., N. Zin. and N. Sahari. 2011a. "Identifying user requirements of mobile government services in malaysia using focus group method”. Journal of e-Government Studies and Best Practices 2: $1-14$. 
11. Al-Thunibat, A., Zin, N. and Sahari, N. 2011c. "Modelling the factors that influence mobile government services acceptance”. African Journal of Business Management. 5(34):13030-13043.

12. Anas, R., H. Al-Soud. S. Al-Yaseen, and H. Al-Jaghoub, 2014. “Jordan's e-Government at the crossroads”. Transforming Government: People, Process and Policy 8(4): 597 - 619

13. Beach, R. 2004. “Adopting Internet technology in manufacturing: a strategic perspective” Production Planning \& Control 15(1): 80-89.

14. Becker, J.M., A. Rai, E.E. Rigdon. 2013. "Predictive validity and formative measurement in structural equation modelling: Embracing practical relevance”. International Conference on Information Systems Milan, December 15-18.

15. Carter, L. and F. Be'langer. 2005. “The utilization of e-government services: citizen trust, innovation and acceptance factors”. Information Systems Journal 15(1): 5-25.

16. Carter, L., 2008. "E-government diffusion: a comparison of adoption constructs”. Transforming Government: People, Process and Policy 2(3): 147 - 161

17. Dahi, M. and Z. Ezziane. 2015. "Measuring e-government adoption in Abu Dhabi with technology acceptance model (TAM)”. International Journal of Electronic Governance 7(3): 206-231.

18. Davis, F. D., 1989. "Perceived usefulness, perceived ease of use, and user acceptance of information technology”. MIS Quarterly 13(3)” 319-339.

19. Deep, M. and G. Sahoo, G. 2011. “M-governance for better G2C service”. Journal of Internet Banking and Commerce 16(1): 1-5.

20. Ekong, U. and V. Ekong. 2010. “M-voting: a panacea for enhanced e-participation”. Asian Journal of Information Technology. 9(2): 111-116.

21. Fornell C and D, Larcker. 1981. "Evaluating Structural Equation Models with Unobservable Variables and Measurement Error”. Journal of Marketing Research, 18(1): 39-50. 
22. Gefen D, D. Straub, and M. Boudreau. 2000. "Structural Equation Modelling and Regression: Guidelines for Research Practice”. Communications of the Association for Information Systems 4(7): $1-77$.

23. Hair J, W. Black, B. Babin, R. Anderson and R. Tatham. 2006. Multivariate Data Analysis (6th ed.).Upper Saddle River, New Jersey: Prentice Hall.

24. Hair, J.F., M. Sarstedt, C.M. Ringle. J. A. Mena. 2012. “An assessment of the use of partial least squares structural equation modeling in marketing research”. Journal of the Academic Marketing Science 40(3): 414-433.

25. Hans, H., J. Stuart, R. Tina, and M. Marcus. 2005. "Driving Consumer Acceptance Of Mobile Marketing: A theoretical framework and empirical study”. Journal of Electronic Commerce Research 6(3): 181-191.

26. Hussein, R., N. Mohamed, A. A. Rahman, and M. Mahmud. 2011. "E-government application: an integrated model on G2C adoption of online tax". Transforming Government: People, Process and Policy 5(3): 225 - 248

27. Islam, Z, S. M. Jasimuddin, and A. Hasan. 2015. “Organizational Culture, Structure, Technology Infrastructure and Knowledge Sharing: Empirical evidence from MNCs based in Malaysia”. VINE: The Journal of Information and Knowledge Systems.45(1): 67-88.

28. Jahanshahi, A., S. Khaksar, N. Yaghoobi and K. Nawaser. 2011 "Comprehensive model of mobile government in Iran”. Indian Journal of Science and Technology 4(9): 1188-1197.

29. Jasimuddin, S. M., J. Li, and N. Perdikis (2015). "Linkage between Geographic Space and Knowledge Transfer at MNCs: A Structural Equation Approach”. Annals of Regional Science 54(3): 769-795.

30. Jasimuddin, S. M., J. Li, and N. Perdikis, N. 2015. “Knowledge recipients, acquisition mechanism and knowledge transfer at Japanese Subsidiaries: An empirical study in China”. Thunderbird International Business Review 57(6): 463-479.

31. Henseler, J., G. Hubona. and P. A. Ray. 2016. "Using PLS path modeling in new technology research: updated guidelines". Industrial Management \& Data Systems 116(1): 2 - 20.

32. Kesavarapu, S. and M. Choi. 2009. "A theoretical framework of knowledge management in mgovernment”. International Journal of Computer and Communication Technology 1(1):.3-13. 
33. Loo, B. and Y. Ngan. 2012. "Developing mobile telecommunications to narrow digital divide in developing countries? Some lessons from China”. Telecommunications Policy 26(1): 888-900.

34. Mahmud, S., A. Norm, Y. K. Dwivedi. 2015. "Examining Adoption Behavior of Mobile Government”. The Journal of Computer Information Systems 53(2): 39-49.

35. McKnight, D. H., V. Choudhury, and C. Kacmar. 2002. “The Impact of Initial Consumer Trust on Intentions to Transact with a Web Site: A Trust Building Model”. Journal of Strategic Information System. 11: 297-323.

36. Mtingwi, J. and J. Belle. 2012. “The state of e-government and m-government readiness in Malawi”. International Journal of Information Technology \& Computer Science (IJITCS) 6(1): 58-68.

37. Nfuka, N. and l. Rusu. 2011. "The effect of critical success factors on IT governance performance.” Industrial Management \& Data Systems 111(9): 1418-1448.

38. Ovais, A. M., J. Markkula, and M. Oivo, 2013. "Factors affecting e-government adoption in Pakistan: a citizen's perspective”. Transforming Government: People, Process and Policy 7(2): 225-239

39. Oye, N. D., N.A. Iahad, and N. Ab.Rahim. 2014. “The history of UTAUT model and its impact on ICT acceptance and usage by academicians”. Educational Information Technology 19(1): 251-270.

40. Pavlou, P.A. and D. Gefen. 2004. "Building Effective Online Marketplaces with Institution-Based Trust”. Information Systems. Research. 15: 37-59.

41. Pavlou, P.A. 2003. “Consumer Acceptance of Electronic Commerce: Integrating Trust and Risk with the Technology Acceptance Model”. International Journal of Electronic Commerce. 7: 101-134.

42. Rehman, M., V. Esichaikul, and M. Kamal. 2012.” Factors influencing e-government Adoption in Pakistan”. Transforming Government: People, Process and Policy 6(3): 258-282.

43. Ringle C, S. Wende, and S. Will. 2005. "SmartPLS 2.0 (M3) Beta, Hamburg http://www.smartpls.de. Sharma S and Gupta J. 2003. 'Building Blocks of an E-Government-A Framework”. Journal of Electronic Commerce in Organizations, 1(4): 1-15.

44. Sperber A. D., R. F. Devellis, and B. Boehlecke. 1994. "Cross-cultural translation: methodology and validation”. Journal of Cross Culture Psychology 25(4): 501-524 
45. Susanto, T. and R. Goodwin. 2008. “A six-level model of SMS-based e-Government”. International Conference on E Government (ICEG) 2008, 23-24 October, Melbourne, Australia.

46. Susanto, T. and R. Goodwin. 2011. "User acceptance of SMS-based e-government services”. $10^{\text {th }}$ International Conference, EGOV 2011, Delft, The Netherlands, 29 August-1 September.

47. Tubadji, A. and P. Nijkamp. 2015. “Cultural impact on regional development” application of a PLS=PM model to Greece”. Annals of Regional Science 54(3): 687-720.

48. Valle, P. O.D. and G. Assaker. 2015. "Using partial least squares structural equation modeling in tourism research: A review of past research and recommendations for future applications”. Journal of Tourism Research, 1-14

49. Warkentin, M., D. Gefen, P. A. Pavlou, G. M. Rose, 2002. "Encouraging Citizen Adoption of EGovernment by Building Trust”. Electronic Marketing 12: 157-162.

50. 50. Weinfurt, K. P. 1995. "Multivariate Analysis of Variance”. In: Grimm LG, Yarnold PR (eds) Reading and Understanding Multivariate Statistics. APA, Washington.

51. Wu, H., A. Ozok, A. Gurses, and J. Wei. 2009. "User aspects of electronic and mobile government: results from a review of current research”. Electronic Government, an International Journal 6(3): 233251.

52. Wu, J. H. and S. C. Wang. 2005. "What Drives Mobile Commerce? : An Empirical Evaluation of the Revised Technology Acceptance Model”. Information \& Management 42(5): 719-729.

53. Yong, L. A., L. B. Hongxiu, K. A. Vassilis, G. A. Jorg,e, H. Simo, and H. Feng. 2014. “An empirical investigation of mobile government adoption in rural China: A case study in Zhejiang province”. Government Information Quarterly 31: 432-442 